\section{Treatment of a refractory biliary stricture after living donor liver transplantation, with a short fully covered metal stent with a long string}

In July 2007, a 56-year-old man with hepatitis B-related cirrhosis and hepatocarcinoma underwent living donor liver transplantation (LDLT), at our institute, using the right lobe graft. We carried out double duct-to-duct biliary anastomoses of the two graft bile ducts - one to the recipient's common hepatic duct and the other to the cystic duct.

In October 2008, the patient had obstructive jaundice, and was diagnosed as hav- ing late biliary strictures involving both anastomoses ( $\bullet$ Fig. 1). Two percutaneous trans-anastomotic biliary catheters were placed. Over the course of 12 months, the patient underwent seven sessions of percutaneous balloon dilation in both anastomoses. Follow-up cholangiography showed resolution of the stricture at the anastomosis with the recipient cystic duct, and persistence of the angulated stricture at the second anastomosis with the common hepatic duct, which was confirmed by magnetic resonance imaging ( $\bullet$ Fig. 2).

Owing to failure of the percutaneous treatment, and to avoid occlusion of the anastomosis to the cystic duct, we placed a short Niti-S biliary, fully covered, selfexpandable metal stent (SEMS; Taewoong Medical Co. Ltd., Seoul, South Korea), $3 \mathrm{~cm}$ in length and $8 \mathrm{~mm}$ in diameter, with an incorporated platinum radiopaquemarked, $10-\mathrm{cm}$ long retrieval string, across the stricture ( Fig.3). The SEMS was removed 3 months later by grasping the string with standard forceps. A final cholangiogram showed resolution of the stricture ( $\bullet$ Fig.4). No further procedure was carried out during the 1 year of follow-up.
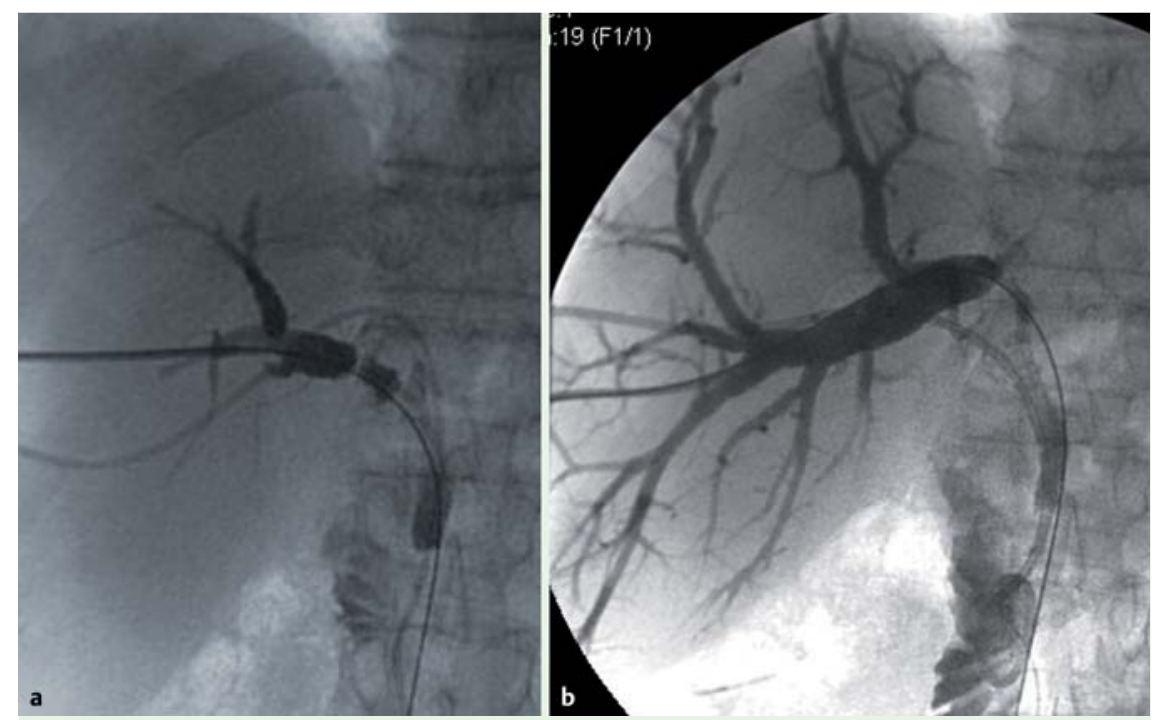

Fig. 1 Percutaneous cholangiography in a 56-year-old man with hepatitis B-related cirrhosis and hepatocarcinoma who underwent living donor liver transplantation (LDLT) showing biliary strictures at the hepatic-cystic duct (a) and hepatic-common hepatic duct (b) anastomoses.
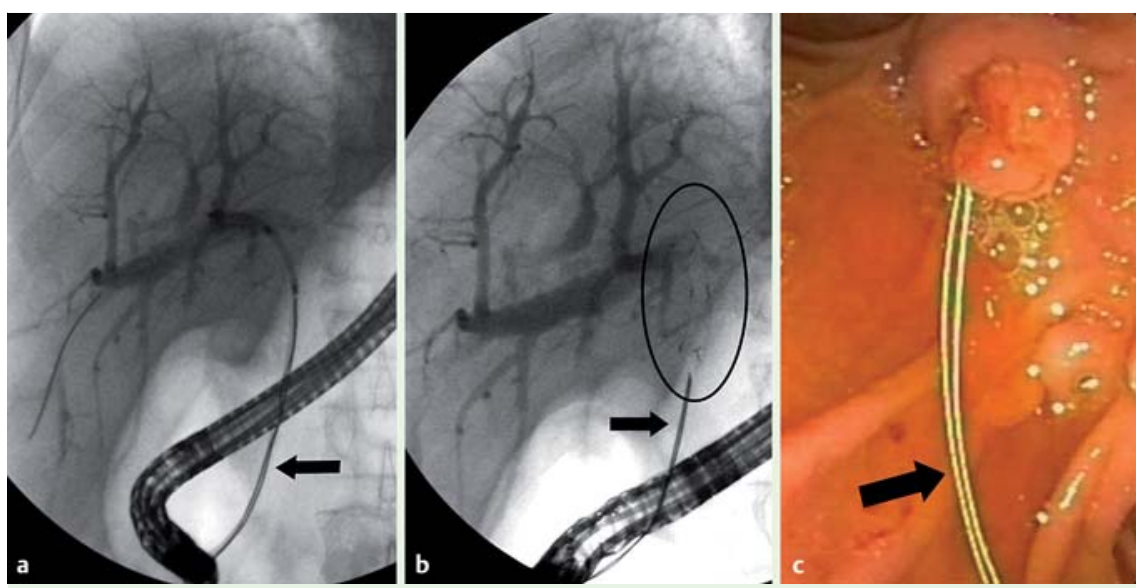

Fig. 3 The self-expanding metallic stent (SEMS) with radiopaque string extending into the duodenum: a, b cholangiographic (black circle) and $\mathbf{c}$ endoscopic views.

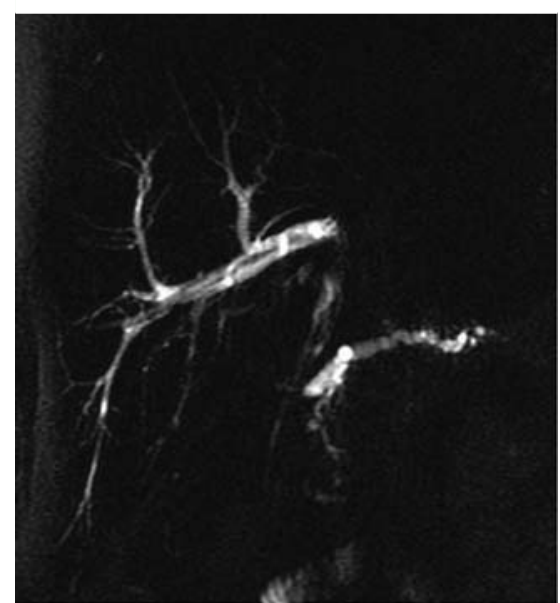

Fig. 2 Magnetic resonance image of the residual hepatic-common hepatic duct stricture.

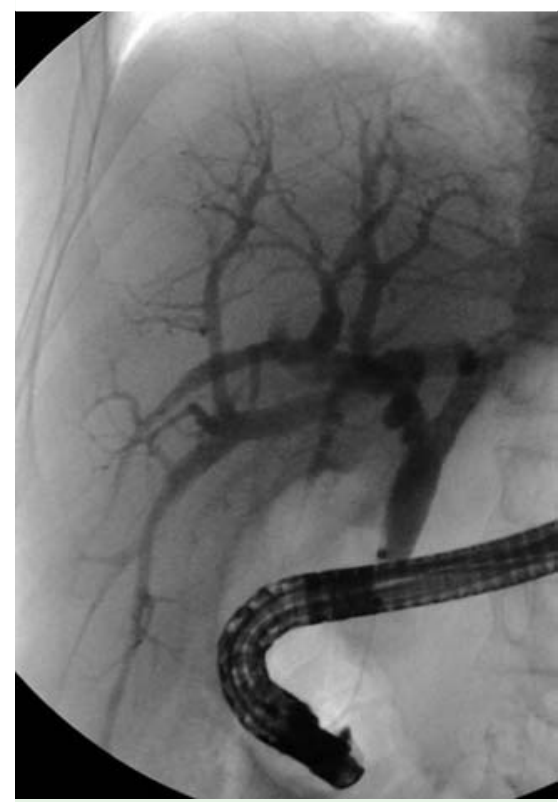

Fig. 4 Final cholangiogram showing resolution of the stricture. 
Biliary complications remain the most common and intractable problem after LDLT, with the incidence of biliary strictures ranging from $3.7 \%$ to $25.3 \%[1,2]$. The use of covered SEMS to treat post-liver-transplantation biliary strictures has been reported [3-5]. This report highlights the feasibility and usefulness of a short SEMS in the treatment of a refractory, and otherwise untreatable, biliary stricture after LDLT with double duct-toduct biliary reconstruction.

Endoscopy_UCTN_Code_TTT_1AR_2AZ

\section{Competing interests: None}

\section{G. Curcio' ${ }^{1}$, M. Traina ${ }^{1}$, R. Miraglia ${ }^{2}$,} I. Tarantino ${ }^{1}$, L. Barresi ${ }^{1}$, A. Granata

${ }^{1}$ Department of Endoscopy, Mediterranean Institute for Transplantation and Advanced Specialized Therapies (IsMeTT), Palermo, Italy

${ }^{2}$ Department of Radiology, Mediterranean Institute for Transplantation and Advanced Specialized Therapies (IsMeTT), Palermo, Italy

\section{References}

1 Wang SF, Huang ZY, Chen XP. Biliary complications after living donor liver transplantation. Liver Transpl 2011; 17: 1127-1136

2 Kasahara M, Egawa H, Takada Y et al. Biliary reconstruction in right lobe living-donor liver transplantation: comparison of different techniques in 321 recipients. Ann Surg 2006; 243: $559-566$

3 Traina $M$, Tarantino I, Barresi $L$ et al. Efficacy and safety of fully covered self-expandable metallic stents in biliary complications after liver transplantation: A preliminary study. Liver Transpl 2009; 15: 1493 - 1498

4 Kahaleh M, Behm B, Clarke BW et al. Temporary placement of covered self-expandable metal stents in benign biliary strictures: a new paradigm? (with video) Gastrointest Endosc 2008; 67: 446-454

5 Tee HP, James MW, Kaffes AJ. Placement of removable metal biliary stent in post-orthotopic liver transplantation anastomotic stricture. World J Gastroenterol 2010; 16: $3597-3600$

\section{Bibliography}

Dol http://dx.doi.org/ 10.1055/s-0031-1291600 Endoscopy 2012; 44: E74-E75

(C) Georg Thieme Verlag KG

Stuttgart · New York

ISSN 0013-726X

\section{Corresponding author}

\section{G. Curcio}

Department of Gastroenterology IsMeTT, UPMC

Via Tricomi 1

Palermo 90127

Italy

Fax: +39-091-2192400

gcurcio@ismett.edu 